\title{
Hydrogen production by reforming methane in a corona inducing dielectric barrier discharge and catalyst hybrid reactor
}

\author{
ZHOU ZhiPeng, ZHANG JiMin, YE TaoHong, ZHAO PingHui \& XIA WeiDong* \\ Department of Thermal Science and Energy Engineering, University of Science and Technology of China, Hefei 230027, China
}

Received January 7, 2011; accepted March 25, 2011

\begin{abstract}
A novel corona inducing dielectric barrier discharge (CIDBD) and catalyst hybrid reactor was developed for reforming methane. This corona inducing technique allows dielectric barrier discharge (DBD) to occur uniformly in a large gap at relatively low applied voltage. Hydrogen production by reforming methane with steam and air was investigated with the hybrid reactor under atmospheric pressure and temperatures below $600^{\circ} \mathrm{C}$. The effects of input power, $\mathrm{O}_{2} / \mathrm{C}$ molar ratio and preheat temperature on methane conversion and hydrogen selectivity were investigated experimentally. It was found that higher methane conversions were obtained at higher discharge power, and methane conversion increased significantly with input power less than $50 \mathrm{~W}$; the optimized molar ratio of $\mathrm{O}_{2} / \mathrm{C}$ was 0.6 to obtain the highest hydrogen selectivity $(112 \%)$; under the synergy of dielectric barrier discharge and catalyst, methane conversion was close to the thermodynamic equilibrium conversion rate.
\end{abstract}

dielectric barrier discharge, methane conversion, corona inducing, hydrogen, catalyst

Citation: Zhou Z P, Zhang J M, Ye T H, et al. Hydrogen production by reforming methane in a corona inducing dielectric barrier discharge and catalyst hybrid reactor. Chinese Sci Bull, 2011, 56: 2162-2166, doi: 10.1007/s11434-011-4485-0

Hydrogen is considered to be an ideal source of energy that could play a key role in fuel cells, combustion engines or gas turbines [1-3]. Currently, the technology of hydrogen storage and transportation is not yet mature. Consequently, the design and operation of compact and distributed hydrogen production devices [4] has attracted considerable interest for combining plasma-chemical activation of reactants with heterogeneous catalysis in hydrogen production [5]. Compared with traditional chemical processes, plasma technology has the potential to allow design of smaller hydrogen production units with the capability of rapid response to load variations, and to offer a unique way to induce gas phase reactions [6].

Non-thermal plasmas have been considered very promising for fuel gas treatment because of their non-equilibrium properties, low power requirement and capacity to induce reactions at relatively low temperatures [6-9]. Non-thermal plasmas that have been applied to hydrogen production in-

*Corresponding author (email: xiawd@ustc.edu.cn) clude gliding arc [10,11], spark discharge [12], corona discharge $[13,14]$, microwave discharge $[1,15]$ and dielectric barrier discharge (DBD) [6,16-19]. DBD is the most commonly used method for atmospheric pressure non- thermal plasma because of its simple device construction and homogeneous distribution of discharge channels [4,20,21]. The shortcoming of DBD is the small discharge gap and demand for high applied voltage due to the approximately 3 $\mathrm{kV} / \mathrm{mm}$ breakdown electric field at atmospheric pressure in air. High applied voltage always results in discharge instability. Indarto [4] investigated hydrogen production by methane reforming with DBD combined with a catalyst based on $\mathrm{Zn}$ and $\mathrm{Cr}$ oxides; the discharge gap of the reactor was $2.9 \mathrm{~mm}$. Pietruszka et al. [5] studied the synergy of DBD and catalyst in hydrogen production, with a $1.5 \mathrm{~mm}$ discharge gap. Nozaki et al. [16] extensively investigated steam reforming of methane in DBD reactors with discharge gaps $0.5,1$ and $3 \mathrm{~mm}$.

Larger discharge gap and volume may be important issues to develop a compact reactor as an in situ hydrogen 
production device[22]. In the present study a novel corona inducing dielectric barrier discharge (CIDBD) reactor with discharge gap $10 \mathrm{~mm}$, with nickel powder uniformly distributed in the discharge zone, was developed to reduce the applied voltage and improve plasma uniformity. A preliminary study of discharge performance was carried out, and the effects of input power, $\mathrm{O}_{2} / \mathrm{C}$ molar ratio and preheat temperature on methane conversion and hydrogen selectivity were investigated experimentally.

\section{Experimental section}

The experimental setup is shown schematically in Figure 1. Methane and air were introduced into the heater at atmospheric pressure via mass flow controllers (Model Sevenstar D07), and the steam flow rate was controlled by adjusting the volume of water flowing into the steam generator. The preheated feed-in gas (methane, air and steam) was then introduced into the DBD reactor. After removing steam through the condenser, the gaseous products were analyzed on-line using a gas chromatograph (Huaai GC9560) equipped with a thermal conductivity detector (TCD).

A schematic diagram of the DBD reactor is shown in Figure 2. The reactor comprised two coaxial quartz tubes: the inner tube with outer diameter $22 \mathrm{~mm}$ filled with metal powder was used as the $\mathrm{HV}$ electrode, and the outer tube with inner diameter $42 \mathrm{~mm}$ wrapped with copper mesh was used as the ground electrode. The discharge gap between the two electrodes was thus $10 \mathrm{~mm}$. The discharge region was $100.5 \mathrm{~cm}^{3}$ in volume and $100 \mathrm{~mm}$ long. A glass fiber insulation layer was wrapped around the outside of the reactor to inhibit heat losses.

The plasma was generated by a high-voltage alternating current (AC) generator with maximum peak voltage $30 \mathrm{kV}$. The power frequency was maintained at $20 \mathrm{kHz}$, while the input discharge power was manipulated by varying the discharge voltage and current which were recorded by a digital storage oscilloscope (Tektronix TDS 2014B). The actual input power was calculated by

$$
P=\text { Frequency } \times \int_{0}^{\tau} i(t) u(t) \mathrm{d} t
$$

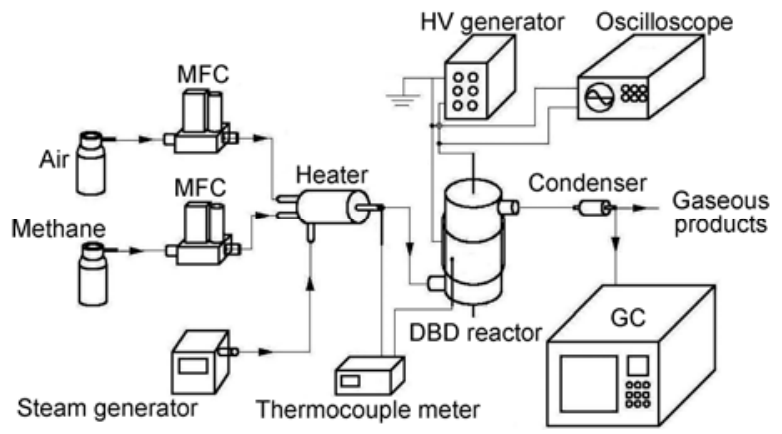

Figure 1 Schematic diagram of experimental apparatus.

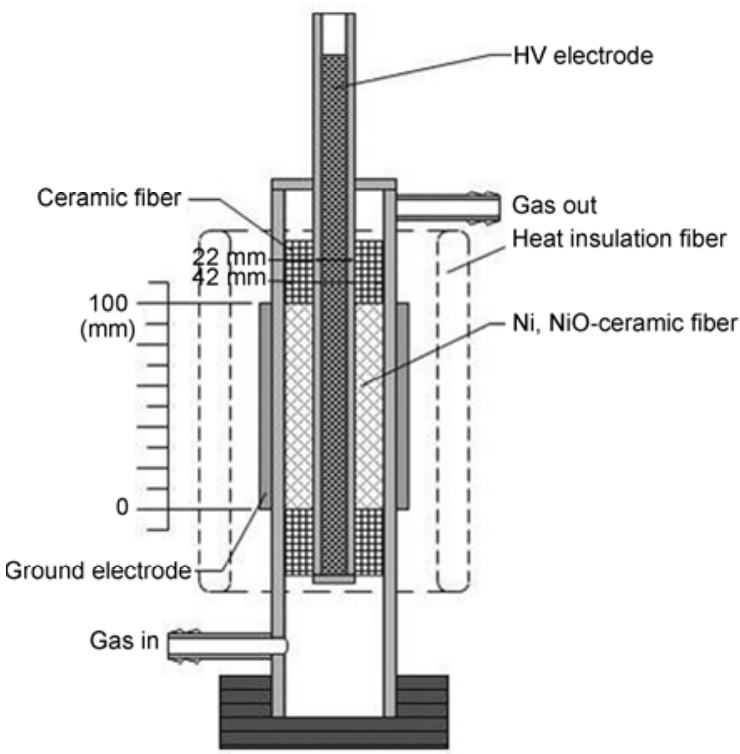

Figure 2 Schematic diagram of DBD reactor.

Methane conversion and hydrogen selectivity were evaluated from

$$
\begin{gathered}
\mathrm{CH}_{4} \text { conversion }=\frac{\text { moles of } \mathrm{CH}_{4} \text { converted }}{\text { moles of } \mathrm{CH}_{4} \text { in feed }} \times 100 \%, \\
\text { Selectivity of } \mathrm{H}_{2}=\frac{\text { moles of } \mathrm{H}_{2} \text { produced }}{2 \times \text { moles of } \mathrm{CH}_{4} \text { converted }} \times 100 \% .
\end{gathered}
$$

To improve the performance of discharge and catalyst, a mixed catalyst of nickel powder $(7 \mathrm{~g}$, average particle size $100 \mu \mathrm{m})$ and $5 \mathrm{wt} \% \mathrm{NiO}$-ceramic fiber $(11.1 \mathrm{~g})$ were added to the discharge zone of the DBD reactor. NiO-ceramic fiber catalysts were prepared using the incipient wetimpregnation method with $\mathrm{NiCl}_{2} \cdot 6 \mathrm{H}_{2} \mathrm{O}$ solution, with ceramic fiber as support. The wet fibers were treated in a Co-60 source with about $60 \mathrm{~Gy} / \mathrm{min}$ radiation dose rate for $12 \mathrm{~h}$, and the fibers were calcined in an oven at $450^{\circ} \mathrm{C}$ for 1 h. Figure 3 shows an SEM image of the NiO-ceramic fiber catalyst; it is apparent that the catalyst was successfully aggregated on the surface of the ceramic fibers.

Nickel powder with small radius of curvature, evenly dispersed in the ceramic fiber catalysts, could lead to uneven distribution of the electric field near the powder surface [23]. Corona discharge should then occur relatively easily under low applied voltage, then induce dielectric barrier discharge.

The experimental conditions were as follows: the inlet $\mathrm{O}_{2} / \mathrm{C}$ molar ratio was varied between 0.1 and 1 ; the inlet $\mathrm{H}_{2} \mathrm{O} / \mathrm{C}$ molar ratio was fixed at 1 ; the inlet methane flow rate was maintained at $0.35 \mathrm{sL} / \mathrm{min}$; the input power was varied from 20 to $100 \mathrm{~W}$; the feed-in gas preheat tempera ure was $200,250,300$ or $350^{\circ} \mathrm{C}$. The temperature of the reactor wall was measured with a thermocouple during the $\mathrm{t}$ entire experiment, and found to be in the range 750-840 K. 


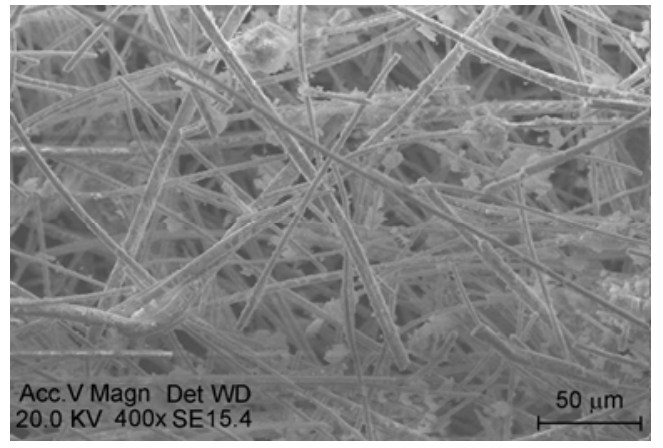

Figure 3 SEM image of NiO-ceramic fiber catalyst.

\section{Results and discussion}

\subsection{Discharge characteristics of corona inducing dielectric barrier discharge}

Typical waveforms of applied voltage and discharge current of DBD (without nickel powder) and CIDBD (with nickel power) are shown in Figure 4(a) and (b), respectively. Discharge was characterized by multiple current pulses of a series of microdischarges per half cycle of the applied volt age [24]. With the same discharge power (about $30 \mathrm{~W}$ ), the applied peak voltages were 17.5 and $13 \mathrm{kV}$ from the sinusoidal voltage curves in Figure 4(a) and (b), respectively. It was confirmed that nickel powder in the discharge zone can significantly reduce the breakdown voltage of DBD, because of the nickel powder distorting the local electric field and generating corona discharge relatively easily.
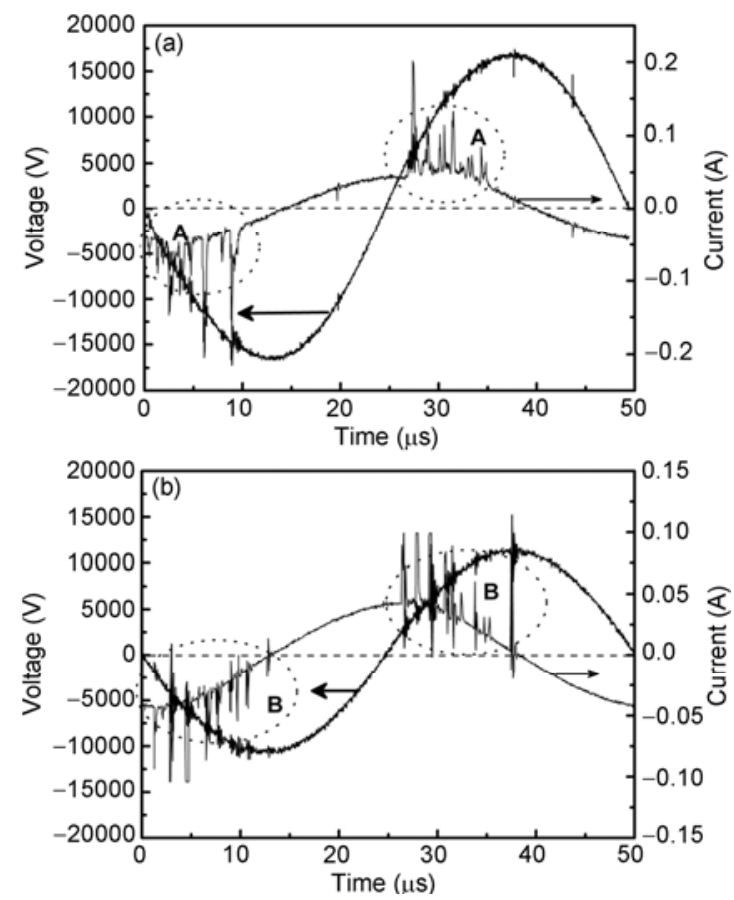

Figure 4 Typical waveforms of the applied voltage and discharge current. (a) DBD (without nickel powder) and (b) CIDBD (with nickel powder).
The discharge current pulses, designated by $\mathrm{A}$ and $\mathrm{B}$ with dashed line circles, showed some differences in discharge performance. In the absence of nickel powder, the amplitude of the larger current pulses exceeded $0.15 \mathrm{~A}$ which randomly combined with small pulses in the range 0.01-0.05 A, and none of the current pulses exceeded 0.15 A with nickel powder. It can be argued that the amount of charge transported in single pulse was more uniform in the presence of nickel power. The duration of microdischarges per half cycle was sustained at about 10 and $14 \mu$ s in the reactor without and with nickel powder, respectively. In other words, the nickel powder extended the duration of microdischarges, and increased the proportion of duty cycle of microdischarges in a whole cycle. It may be concluded that nickel powder or any other conducting small particle dispersed in the discharge zone could generate CIDBD stably and uniformly, and thus is more favorable for production of energetic electrons and active radical species rather than heat losses. The electrical energy consumption of DBD is generally divided in two parts: one part for generating high-energy electrons and active radical species, and another part for heating. In the high-performance DBD reaction system only $20 \%$ of the electrical energy was lost as heat, whereas the energy consumption on heating increased to $85 \%$ in an unoptimized system [18].

\subsection{Effect of experimental parameters on methane conversion}

Figure 5 shows the effect of feed-in gas preheat temperature on methane conversion at constant input power $(27 \mathrm{~W})$. The molar ratio of $\mathrm{O}_{2} / \mathrm{C}$ was set to $0.25,0.5$ and 0.75 and the feed-in gas temperature was set to $200,250,300$ and $350^{\circ} \mathrm{C}$. It can be seen that higher molar ratio of $\mathrm{O}_{2} / \mathrm{C}$ led to higher methane conversion, and the changes in the absolute value of methane conversion at the same $\mathrm{O}_{2} / \mathrm{C}$ molar ratio were less than $2 \%$. The influence of feed-in gas preheat temperature was negligible, which is agreement with previous work reported by Lü et al. [25]. To avoid excessive heat losses

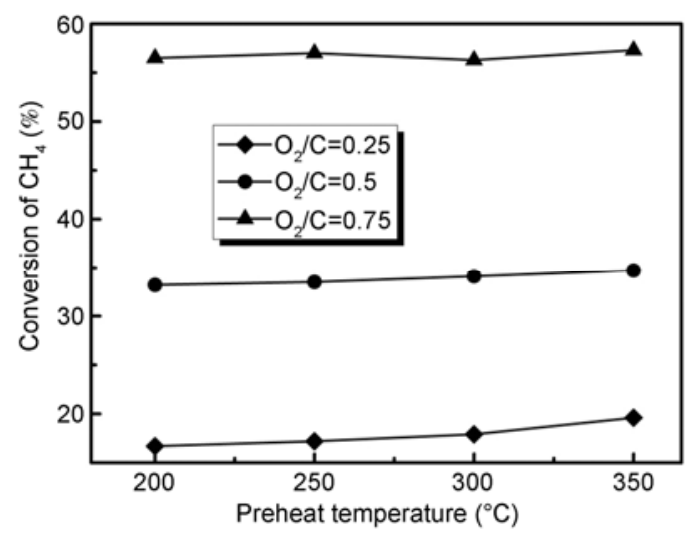

Figure 5 Methane conversion changes with preheat temperature at various $\mathrm{O}_{2} / \mathrm{C}$ molar ratios (input power $27 \mathrm{~W}$ ). 
and improve the system energy efficiency the preheat temperature was kept at $200^{\circ} \mathrm{C}$ in subsequent experiments to avoid steam liquefaction.

The effect of input power on the conversion of methane is shown in Figure 6. Generally speaking, larger $\mathrm{O}_{2}$ content resulted in higher conversion of methane. Methane conversion increased significantly with increase of input power, and reached a plateau for input power higher than $50 \mathrm{~W}$ at a given oxygen content. Vibrationally excited methane molecules are more easily generated by electron impact because of $\mathrm{CH}_{4}$ having a larger collision cross section than the feed-in gas molecules. Methane molecules in vibrationally excited states in stretching mode are 1600 times more reactive than ground state molecules on a catalyst surface [26]. The synergy of DBD and catalysts in enhancing chemical reactions is due mainly to the following three paths [18]. (1) Active radical species and ions are decomposed on the catalyst at a lower temperature than are the ground state molecules. (2) Byproducts such as acetylene and ethane decompose at lower temperatures than methane. The lifetimes of these products are sufficiently long for them to reach the surface of catalyst and to be decomposed. (3) Heat generated by DBD also enhances the regular thermal reaction. It can be concluded that paths (1) and (2) dominate the enhancement of reactions when the input power is less than 50 W. With further increase of input power the methane conversion approaches the thermodynamic equilibrium value, and the heat generated by DBD has much less effect on the reaction.

\subsection{Effect of experimental parameters on hydrogen selectivity}

Figure 7 shows that the influence of input power on hydrogen selectivity is not significant under the conditions tested, whereas the $\mathrm{O}_{2} / \mathrm{C}$ molar ratio plays a key role in the hydrogenselectivity. Considered together with the influence of the input power on methane conversion, it seems that the plasma effectively promotes methane conversion but has a less er effect on hydrogen production. The hydrogen selectivity

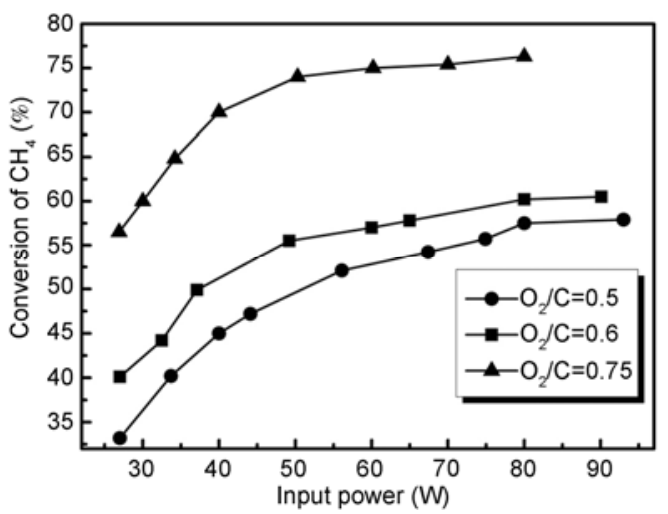

Figure 6 Methane conversion changes with input power at various $\mathrm{O}_{2} / \mathrm{C}$ molar ratios (preheat temperature $200^{\circ} \mathrm{C}$ ).

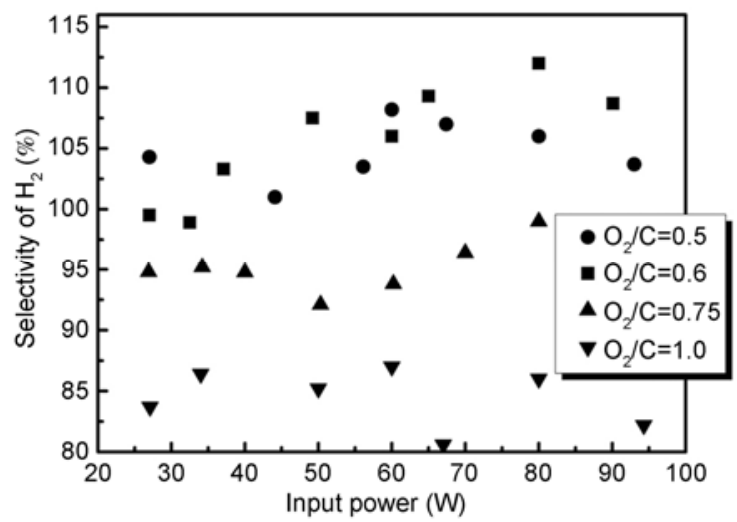

Figure 7 Hydrogen selectivity changes with input power at various $\mathrm{O}_{2} / \mathrm{C}$ molar ratios (preheat temperature $200^{\circ} \mathrm{C}$ ).

was greater than $100 \%$ for $\mathrm{O}_{2} / \mathrm{C}$ molar ratios 0.5 and 0.6 , and the highest hydrogen selectivity was $112 \%$.

\subsection{Comparison of simulated and experimental data}

Figure 8 shows a comparison of simulated values of methane conversion and hydrogen selectivity with experimental data, at various $\mathrm{O}_{2} / \mathrm{C}$ molar ratios. The simulated values were calculated using CHEMKIN software (thermodynamic equilibrium temperature $800 \mathrm{~K}, \mathrm{H}_{2} \mathrm{O} / \mathrm{C}=1$ ). The experimental conditions were as follows. The feed-in gas temperature was kept constant at $200^{\circ} \mathrm{C}$, and the input power was $80 \mathrm{~W}$. Good correlation was obtained between the calculations and the experimental results for methane conversion. We did not achieve higher than equilibrium methane conversion that was reported previously [16]. In our experiments methane conversion was governed by thermodynamic equilibrium because of the presence of catalysts and the occurrence of the following reverse reactions.

$$
\begin{gathered}
\mathrm{CO}_{2}+4 \mathrm{H}_{2} \leftrightarrow \mathrm{CH}_{4}+2 \mathrm{H}_{2} \mathrm{O}, \\
\mathrm{CO}+3 \mathrm{H}_{2} \leftrightarrow \mathrm{CH}_{4}+\mathrm{H}_{2} \mathrm{O} .
\end{gathered}
$$

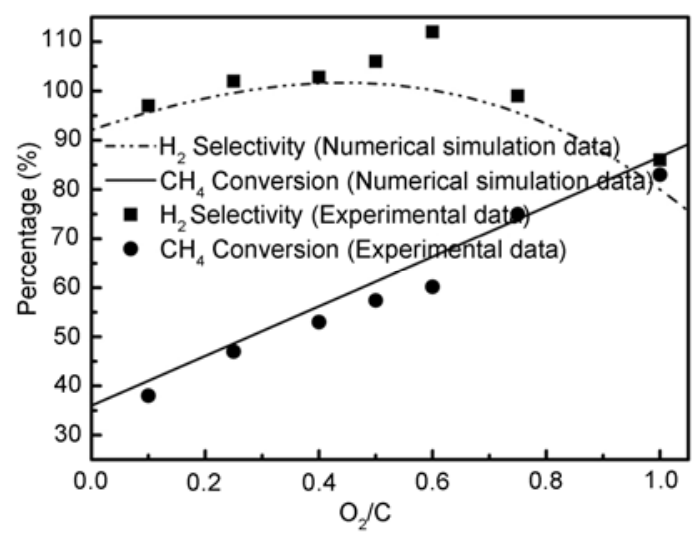

Figure 8 Comparison of numerical simulation and experimental data for various $\mathrm{O}_{2} / \mathrm{C}$ molar ratios. 
The reverse reactions were reported by Nozaki et al. [18], and even if methane conversion exceeds equilibrium because of the synergistic effect of excited species generated by CIDBD, the reverse reactions limit that synergistic effect. The conversion of methane in our experiments was not more than $80 \%$, hence it is necessary to focus on changing the composition and structure of the catalyst to inhibit reverse reactions.

\section{Conclusions}

Hydrogen production by reforming methane with steam and air was investigated in a corona inducing dielectric barrier discharge and catalyst hybrid reactor. The following conclusions can be drawn from the experimental results. (1) Compared to traditional DBD, corona inducing dielectric barrier discharge (CIDBD) is more stable and uniform with lower breakdown voltage; (2) input discharge power and inlet molar ratio of $\mathrm{O}_{2} / \mathrm{C}$ are key factors affecting the conversion of methane, but only the molar ratio of $\mathrm{O}_{2} / \mathrm{C}$ affects the hydrogen selectivity; (3) the range of suitable $\mathrm{O}_{2} / \mathrm{C}$ molar ratios is $0.5-0.75$, the feed-in gas should be preheated to a temperature not higher than $200^{\circ} \mathrm{C}$, and the optimal input power is $50-60 \mathrm{~W}$; (4) although the fundamental reaction mechanism of the plasma chemical process is not clearly understood, methane conversion in this study was governed by thermodynamic equilibrium.

This work was supported by the National High Technology Research and Development Program of China (2007AA05Z105) and the National Natural Science Foundation of China (50876101 and 51006095).

1 Cai J L, Wang G C, Li Y C, et al. Enrichment and hydrogen production by marine anaerobic hydrogen-producing microflora. Chinese Sci Bull, 2009, 54: 2656-2661

2 Jasinski M, Dors M, Mizeraczyk J. Production of hydrogen via methane reforming using atmospheric pressure microwave plasma. J Power Sources, 2008, 181: 41-45

3 Bromberg L, Cohn D R, Rabinovich A, et al. Plasma catalytic reforming of methane. Int J Hydrogen Energy, 1999, 24: 1131-1137

4 Indarto A. Hydrogen production from methane in a dielectric barrier discharge using oxide zinc and chromium as catalyst. J Chin Inst Chem Eng, 2008, 39: 23-28

5 Pietruszka B, Anklam K, Heintze M. Plasma-assisted partial oxidation of methane to synthesis gas in a dielectric barrier discharge. Appl Catal A: Gen, 2004, 261: 19-24

6 Hammer T, Kappes T, Baldauf M. Plasma catalytic hybrid processes: Gas discharge initiation and plasma activation of catalytic processes. Catal Today, 2004, 89: 5-14
7 Indarto A, Chio J W, Lee H, et al. The kinetic studies of direct methane oxidation to methanol in the plasma process. Chinese Sci Bull, 2008, 53: 2783-2792

8 Bromberg L, Cohn D R, Rabinovich A, et al. Emissions reductions using hydrogen from plasmatron fuel converters. Int J Hydrogen Energy, 2001, 26: 1115-1121

9 Petitpas G, Rollier J D, Darmon A, et al. A comparative study of non-thermal plasma assisted reforming technologies. Int J Hydrogen Energy, 2007, 32: 2848-2867

10 Cormier J M, Rusu I. Syngas production via methane steam reforming with oxygen: plasma reactors versus chemical reactors. J Phys D: Appl Phys, 2001, 34: 2798-2803

11 Zheng B, Yan J H, Li X D, et al. Plasma assisted dry methane reforming using gliding arc gas discharge: Effect of feed gases proportion. Int J Hydrogen Energy, 2008, 33: 5545-5553

12 Horng R F, Huang H H, Lai M P, et al. Characteristics of hydrogen production by a plasma-catalyst hybrid converter with energy saving schemes under atmospheric pressure. Int J Hydrogen Energy, 2008, 33: 3719-3727

13 Le H, Lobban L L, Mallinson R G. Some temperature effects on stability and carbon formation in low temperature ac plasma conversion of methane. Catal Today, 2004, 89: 15-20

14 Supat K, Chavadej S, Lobban L L, et al. Combined steam reforming and partial oxidation of methane to synthesis gas under electrical discharge. Ind Eng Chem Res, 2003, 42: 1654-1661

15 Bang C U, Hong Y C, Cho S C, et al. Methane augmented microwave plasma burner. IEEE Trans Plasma Sci, 2006, 34: 1751-1756

16 Nozaki T, Muto N, Kado S, et al. Dissociation of vibrationally excited methane on $\mathrm{Ni}$ catalyst Part 1 application to methane steam reforming. Catal Today, 2004, 89: 57-65

17 Wang B W, Zhang X, Liu Y W, et al. Conversion of $\mathrm{CH}_{4}$, steam and $\mathrm{O}_{2}$ to syngas and hydrocarbons via dielectric barrier discharge. J Nat Gas Chem, 2009, 18: 94-97

18 Nozaki T, Hiroyuki T, Okazaki K. Hydrogen Enrichment of Low-calorific fuels using barrier discharge enhanced $\mathrm{Ni} / \mathrm{Al}_{2} \mathrm{O}_{3}$ bed reactor: Thermal and nonthermal effect of non-equilibrium plasma. Energ Fuel, 2006, 20: 339-345

19 Nozaki T, Fukui W, Okazaki K. Reaction enhancement mechanism of the nonthermal discharge and catalyst hybrid reaction for methane reforming. Energ Fuel, 2008, 22: 3600-3604

20 Yang Y. Methane conversion and reforming by nonthermal plasma on pins. Ind Eng Chem Res, 2002, 41: 5918-5926

21 Matin N S, Savadkoohi H A, Feizabadi S Y. Methane conversion to $\mathrm{C}_{2}$ hydrocarbons using dielectric-barrier discharge reactor: Effects of system variables. Plasma Chem Plasma Process, 2008, 28: 189-202

22 Thammanoon S, Piyaphon T, Sumaeth C. Partial oxidation of methane with air for synthesis gas production in a multistage gliding arc discharge system. Int J Hydrogen Energy, 2007, 32: 1067-1079

23 Raizer Y P. Gas Discharge Physics. Berlin: Springer-Verlag, 1991

24 Tang J, Duan Y X, Zhao W. Characterization and mechanism studies of dielectric barrier discharges generated at atmospheric pressure. Appl Phys Lett, 2010, 96: 191503

25 Lü J, Li Z H. Conversion of natural gas to $\mathrm{C}_{2}$ hydrocarbons via cold plasma technology. J Nat Gas Chem, 2010, 19: 375-379

26 Juurlink L B F, McCabe P R, Smith R R, et al. Eigenstate-resolved studies of gas-surface reactivity: $\mathrm{CH}_{4}(\mathrm{v} 3)$ dissociation on $\mathrm{Ni}(100)$. Phys Rev Lett, 1999, 83: 868-871

Open Access This article is distributed under the terms of the Creative Commons Attribution License which permits any use, distribution, and reproduction in any medium, provided the original author(s) and source are credited. 